\title{
Anesthetic management of the removal of a giant metastatic cardiac liposarcoma occupying right ventricle and pulmonary artery
}

\author{
Jianhong $\mathrm{Xu}^{1+}$, Yueying Zheng ${ }^{1+}$, Liqing Wang ${ }^{1}$, Qiang Feng ${ }^{2}$, Ceyan $\mathrm{Yu}^{2}$ and Shengmei Zhu ${ }^{1 *}$
}

\begin{abstract}
A 60 years old chinese male scheduled for a removal of an intracardiac mass occupying majority of right ventricular space, right ventricular outflow tract and pulmonary artery. The giant cardiac mass was later diagnosed pathologically as metastatic liposarcoma. The patient had a history of surgical removal of myxoid liposarcoma from his left thigh many years ago. It is extremely rare for liposarcoma to metastatize to right ventricle and pulmonary artery. The anesthetic management of the surgical procedure to remove this kind of intracardiac mass poses significant challenges to anesthesia providers. Our patient developed refractory hypotension after induction of general anesthesia which necessitated urgent cardiopulmonary bypass. The surgical procedure was successful and the patient recovered from the surgery and was discharged home without significant complication. Accurate preoperative diagnosis and assessment of patient's functional status, appropriate preoperative volume status, emergency cardiopulmonary bypass readiness, smooth and gentle induction of general anesthesia with less myocardial depressing agent, and closely monitoring patient's vitals and hemodynamic parameters are imperative in managing this kind of patients.
\end{abstract}

Keywords: Liposarcoma, Cardiac tumor, Hypotension, Cardiopulmonary bypass, Transesophageal echocardiography

\section{Background}

Metastatic tumors to cardiac chamber(s) are uncommon. If it occurs, mostly it is due to renal cancer and metastasized to right atrium. Liposarcoma from lower extremity metastasized into right ventricle (RV) and protruded into pulmonary artery (PA) is extremely rare [1-4]. We report this case with the metastatic neoplasm occupying most RV chamber space and protruding into pulmonary artery. When we induced general anesthesia, the patient collapsed hemodynamically. Emergency cardiopulmonary bypass (CPB) was established. The patient underwent a successful removal of the metastatic tumor and recovered smoothly postoperatively. The complete resection of tumor is a recognized therapy with documented favorable prognosis [5]. The scheduled procedure in this kind of patient poses unique challenges to the anesthesiologist(s). We will

\footnotetext{
* Correspondence: smzhu20088@163.com

${ }^{\dagger}$ Equal contributors

${ }^{1}$ Department of Anesthesiology, The First Affiliated Hospital, School of

Medicine, Zhejiang University, 79 Qingchun Road, Hangzhou 310003, China
}

Full list of author information is available at the end of the article discuss what we have learned from this case and the potential challenges anesthesia provider(s) will face.

\section{Case presentation}

A 60 years old chinese male was admitted to our hospital with chest tightness, dyspnea, systemic edema, and abdominal distension for more than 1 week. Physical examination is within normal limits except mild systematic edema. Electrocardiography (ECG) showed complete right bundle branch block and RV hypertrophy. The chest Xray revealed cardiomegaly (cardiothoracic ratio: 60\%). The transthoracic echocardiography detected a large echogenic mass $(10.4 * 4.1 \mathrm{~cm})$ which occupied most chamber space of RV and RV outflow tract (RVOT), was attached to the $\mathrm{RV}$ free wall, and extended into the main pulmonary artery and its bifurcations. A small pericardial effusion and left ventricular diastolic dysfunction were also detected. Computerized tomography (CT) with contrast of the chest confirmed the presence of the mass, which caused obvious obstruction of the RVOT (Figure 1). Laboratory results were unremarkable. The patient had a right bundle branch 


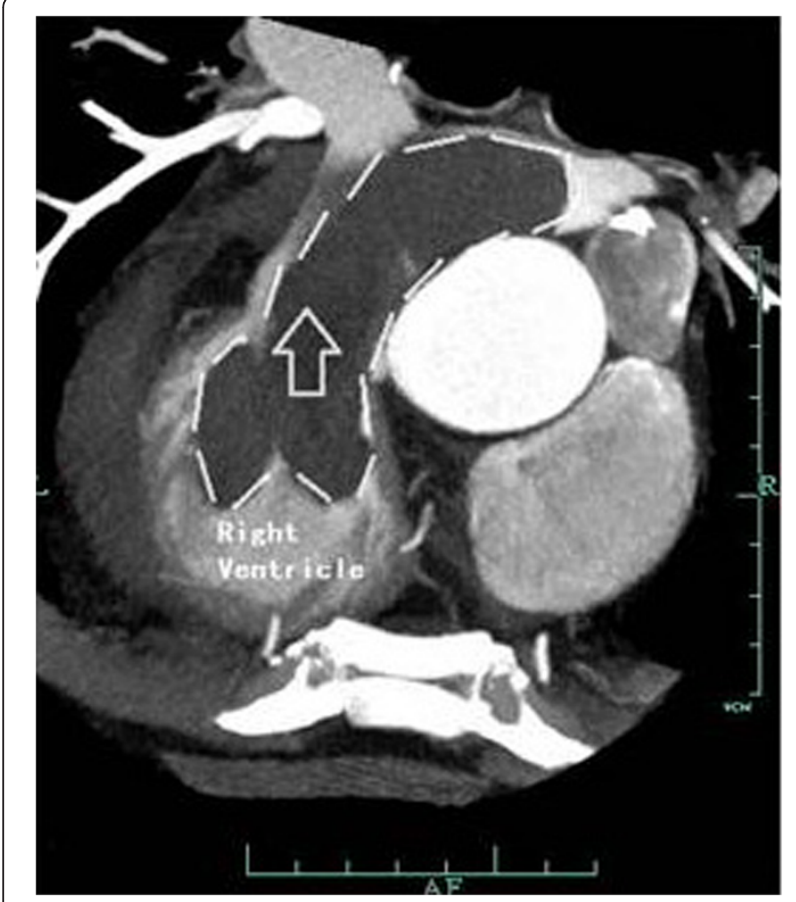

Figure 1 lodine enhanced computerized tomography of the patient's chest. Sagittal view confirmed a large filling defect in the right ventricle extended into the right pulmonary artery (arrow), rending almost complete occlusion of the right ventricular outflow tract.

block for about 10 years and a surgical removal of a left thigh liposarcoma 20 years ago. With the preoperative diagnosis of intracardia tumor, the patient was scheduled for excision of the mass with CPB. On arrival to operating theatre, $\mathrm{O}_{2}(5 \mathrm{~L} / \mathrm{min})$ via face mask was administered and all American Society of Anesthesiologists (ASA) standard monitors were started. Pulse oxygen saturation $\left(\mathrm{SpO}_{2}\right)$ was $98 \%$, and heart rate 100 beats/min. The left radial arterial and large-bore intravenous access was obtained. The invasive blood pressure was 120/85 mmHg (mean blood pressure, MBP, $100 \mathrm{mmHg}$ ). A double-lumen central venous catheter (14, 18gauge, $13 \mathrm{~cm}$ length from the catheter tip to the skin; Arrow International, USA) was inserted to the right internal jugular vein before the induction of general anesthesia. Then the central venous pressure (CVP) was measured as $31 \mathrm{mmHg}$. Lactate Ringer's solution $1000 \mathrm{ml}$ was administrated, and then the induction of general anesthesia was performed slowly with midazolam $2 \mathrm{mg} \mathrm{iv}$, etomidate $8 \mathrm{mg} i v$, rocuronium $50 \mathrm{mg}$ $i v$, sufentanyl $30 \mu \mathrm{g} i v$, and scopolamine $0.3 \mathrm{mg} i v$. During induction, blood pressure fell about $40 \mathrm{mmHg}$ from baseline, which responded to phenylephrine $(40 \mu \mathrm{g}, i v)$ and fluid administration. The results from arterial blood gas revealed $\mathrm{pH}$ 7.30, $\mathrm{PaCO}_{2} 37, \mathrm{PaO}_{2} 89\left(\mathrm{FiO}_{2}\right.$ at 50\%). General anesthesia was maintained with propofol $(200 \mathrm{mg} / \mathrm{h})$ and cis-atracurium $(10 \mathrm{mg} / \mathrm{h})$, and sufentanyl ( $i v$, intermittently according to hemodynamic changes). Meanwhile, dopamine (3-8 $\mu \mathrm{g} / \mathrm{kg} / \mathrm{min})$ was given continuously. MBP decreased below $60 \mathrm{mmHg}$ after sternal retraction, unresponsive to intravenous fluid and phenylephrine administration. Heart rates fluctuated around 90 beats $/ \mathrm{min}$. $\mathrm{SpO}_{2}$ maintained at $95-100 \%$. CVP increased to $35 \mathrm{mmHg}$. The medication for maintenance of general anesthesia was turned down temporarily. About 24 minutes after induction of general anesthesia, urgent $\mathrm{CPB}$ was initiated after intravenous heparine was given. Ulinastatin (30,000 U) and methylprednisolone $(40 \mathrm{mg})$ were also administrated. Then the surgery team removed the neoplasm successfully from the RV, RVOT and pulmonary artery. Total CPB and aortic cross-clamp times were 90 and 24 minutes, respectively. The patient was weaned from $\mathrm{CPB}$ easily with pacemaker and epinephrine infusion of $6 \mu \mathrm{g} / \mathrm{min}$. At the termination of $\mathrm{CPB}$, the $\mathrm{pH}$ was $7.30, \mathrm{PaCO}_{2} 44 \mathrm{mmHg}$, $\mathrm{PaO}_{2} 276 \mathrm{mmHg}$ with $\mathrm{FiO}_{2} 80 \%$. After CPB, the patient's heart rate was maintained at around 90 beats $/ \mathrm{min}$, blood pressure 90-100/50-60 mmHg, and CVP 9-11 mmHg. The patient was extubated at postoperative day one in surgical ICU (intensive care unit) and he was discharged home in a good condition 11 days postoperatively. The final histopathology report of the tumor mass revealed myxoid liposarcoma. The post-operative ECG indicated no residual mass was inside the heart chambers.

\section{Discussion}

The occurrence of metastatic liposarcoma to the heart is rare. Metastatic liposarcoma occurs most likely in the lungs, liver, lymph node, brain and skeletal system [6]. Only 20 cases of metastatic cardiac liposarcoma were reported in the literature prior to our report [4,7-9]. Diagnosis of the isolated heart tumor as being metastatic is unusual unless the primary site is discovered. Liposarcoma is one of the most common soft tissue sarcomas, usually found in the lower extremities. The myxoid of histological classification accounts about $50 \%$ in liopsarcoma subgroups, which is characterized by a slow growth and a low risk for the metastasis. Some authors believe that it may take 3-25 years to present at a metastatic location [6]. In our patient, the interval between the appearance of primary tumor and metastasis was about 20 years.

Clinically, the symptoms of cardiac metastasis are basically nonspecific. Pericardium is usually involved and pericardial effusion often exists. Heart failure is a common clinical feature. And cardioembolic stroke, myocardial infarction and even death from malignant arrhythmia may be its serious complications. Generally, cardiac symptoms appear slowly in onset. Nevertheless, in our case, symptoms on admission were 1-week history of clinical symptoms related to the right heart failure. Two-dimensional ECG and CT of the chest are reportedly very accurate in making the diagnosis and assessing the extent of a cardiac mass preoperatively, though angiocardiography would 
better provide spatial and temporal resolution in this kind of patients [10]. The prognosis of the metastatic liposarcoma is usually poor. Surgery is indicated when complete resection of tumor is feasible and/or relieving intracardiac obstruction is necessary [11].

The concerns in anesthetizing these patients with tumors involved in the RV, the RVOT, and even PA include acute RV failure, hypoxemia, low cardiac output, tamponade, and potential pulmonary emboli. There is no "standard method" for the anesthetic management of this kind of surgical procedures. We believe the following strategies will help manage these patients:

1. Preoperative evaluation: accurate preoperative diagnosis, assessment of tumor size, location, involvement of cardiac valves, tumor mobility, degree of obstruction to blood flow etc and evaluation of patient's overall cardiac functional status and comorbidities;

2. Preoperative volume replacement is very important, hypovolemia should be avoided;

3. Monitoring: non-thermodilution technique for cardiac output measurement should be used, because we cannot insert a pulmonary artery catheter for these patients. CVP is possible, but the catheter cannot be too close to superior vena cava-right atrium junction; Transesophageal ECG will be very helpful in multiple aspects: confirming diagnosis, assessment of the mass, evaluation of blood volume status, cardiac function and comorbidities, monitoring the evolving process of the surgical procedure. In addition, it is useful in detecting the tumor fragmentation, dislodgement or embolism [12,13]. Unfortunately we did not use TEE (transesophageal echocardiography) due to technical difficulties.

4. Emergency CPB readiness: sedating patient for preoperative invasive line placement, or inducing general anesthesia can all cause hemodynamic collapse, so emergency CPB readiness is mandatory. Surgical sterilizing and draping before the initiation of induction of anesthesia is also mandatory. In some report, some authors even suggested to prepare for femoral-femoral cannulation and bypass [12].

5. Smooth and slow-titration induction of general anesthesia with less myocardial depressing agent, and closely monitoring patient's vitals and hemodynamic parameters are imperative in managing this kind of patients. Avoidance of sedating these patients outside of operation room (OR) is also very important because if patient's hemodynamic parameters worsen, emergency $\mathrm{CPB}$ is necessary, it is more favorable if patient is inside the OR.

6. Judicious use of inotropes: inotropes are doublesides sword for these kinds of patients. When using appropriately, inotropes can enhance myocardial contractility and improve hemodynamics. On the other hand, inotropes can also cause increased contractility which leads to narrower passage for intracardiac blood flow.

We supplemented the patient with $1000 \mathrm{ml}$ of crystalloid before the initiation of induction. However, we were not sure whether the RV preload was full, since the CVP monitoring might not accuratly reflect the RV volume status due to the RV mass. Despite of the slow and careful induction of anesthesia and intravenous infusion of dopamine for improving RV contractility, hypotension happened after induction and exacerbated after sternotomy. This hypotension might be related to decreased systemic vascular resistance (SVR), which caused decreased venous return, thus lower cardiac output and hypotension. Another potential mechanism is the sudden dilatation of RV. Flexman AM et al reported with TEE monitoring that the distended RV in the condition of acute RV failure forced the interventricular septum to be shifted the left, which reduced the left ventricle volume further [12]. In our case, the surgeon did find the heart congestion during the exploration. Undoubtedly, TEE measurements would be significantly useful and helpful for cardiac assessment and monitoring. In addition, delicate performance during surgery is also crucial for the patient. The surgery team adopted a special technique of suctioning tumor instead of excision avoid tumor fragmentation, thus reducing the chance of residual tumor or tumor migration to other tissue or organs. Post-operative ECG assesses the completeness of surgical removal and may reveal some unexpected findings.

\section{Conclusions}

Giant metastatic cardiac liposarcoma occupying right ventricle and pulmonary artery is extremely rare. The anesthetic management of the surgical procedure to remove this kind of tumor poses significant challenges to anesthesia providers. Accurate preoperative diagnosis and assessment of patient's functional status, appropriate preoperative volume status, emergency $\mathrm{CPB}$ readiness, smooth and gentle induction of general anesthesia with less myocardial depressing agent, and closely monitoring patient's vitals and hemodynamic parameters are imperative in managing this kind of patients.

\section{Consent statement}

Written informed consent was obtained from the patient for publication of this case report and any accompanying images. A copy of the written consent is available for review by the Editor-in-Chief of this journal. 


\section{Abbreviations}

ASA: American society of anesthesiologists; CPB: Cardiopulmonary bypass; $\mathrm{CT}$ : Computerized tomography; CVP: Central venous pressure;

ECG: Electrocardiography; ICU: Intensive care unit; MBP: Mean blood pressure; OR: Operation room; PA: Pulmonary artery; RV: Right ventricle; RVOT: Right ventricular outflow tract; $\mathrm{SpO}_{2}$ : Pulse oxygen saturation; SVR: Systemic vascular resistance; TEE: Transesophageal echocardiography.

\section{Competing interests}

The authors declare that they have no competing interests.

\section{Authors' contributions}

$\mathrm{XJH}$ and ZSM carried out the anesthetic management of the patient. ZYY participated in the following-up of this patient and drafted the manuscript. WLQ participated in modify the manuscript and submitted to the journal. FQ and YCY participated in the operation of this patient. All authors read and approved the final manuscript.

\section{Acknowledgement}

All the people we acknowledge are listed in the authorship. This article is supported by a national clinical key specialty construction projects in CHINA.

\section{Author details}

'Department of Anesthesiology, The First Affiliated Hospital, School of Medicine, Zhejiang University, 79 Qingchun Road, Hangzhou 310003, China. ${ }^{2}$ Department of Thoracicardiology, The First Affiliated Hospital, School of Medicine, Zhejiang University, 79 Qingchun Road, Hangzhou 310003, China.

Received: 29 August 2013 Accepted: 17 March 2014

Published: 22 March 2014

\section{Reference}

1. Tong EC, Rubenfeld S: Cardiac metastasis from myxoid liposarcoma emphasizing its radiosensitivity. Am J Roentgenol Radium Ther Nucl Med 1968, 103:792-799.

2. Langlard JM, Lefévre M, Fiche M, Chevallier JC, Godin O, Bouhour JB: [Right atrioventricular metastasis of myxoid liposarcoma. Prolonged course after repeated surgery and chemotherapy]. Arch Mal Coeur Vaiss 1992, 85:1353-1356.

3. Kono T, Amano J, Sakaguchi M, Kitahara H: Successful resection of cardiac metastatic liposarcoma extending into the SVC, right atrium, and right ventricle. J Card Surg 2005, 20:364-365.

4. Mitomi M, Kimura K, Iguchi Y, Hayashida A, Nishimura H, Irei I, Okawaki M, Ikeda $\mathrm{H}$ : A case of stroke due to tumor emboli associated with metastatic cardiac liposarcoma. Intern Med 2011, 50:1489-1491.

5. Hallahan DE, Vogelzang NJ, Borow KM, Bostwick DG, Simon MA: Cardiac metastases from soft-tissue sarcomas. J Clin Oncol 1986, 4:1662-1669.

6. Ravikumar TS, Topulos GP, Anderson RW, Grage TB: Surgical resection for isolated cardiac metastases. Arch Surg 1983, 118:117-120.

7. Fairman EB, Mauro VM, Cianciulli TF, Rubio M, Charask AA, Bustamante J, Barrero CM: Liposarcoma causing left ventricular outflow tract obstruction and syncope: a case report and review of the literature. Int J Cardiovasc Imaging 2005, 21:513-518.

8. Chughtai A, Cronin P, Lucas DR, Prager R, Kazerooni EA: Metastatic shoulder liposarcoma to the right ventricle: CT findings. J Thorac Imaging 2007, 22:195-198.

9. Dogan U, Zamani A, Gormus N, Paksoy Y, Avunduk MC, Demirbas S: The first case report of a metastatic myxoid liposarcoma invading the left atrial cavity and pulmonary vein. Heart Surg Forum 2011, 14:E261-E263.

10. Godwin JD, Axel L, Adams JR, Schiller NB, Simpson PC Jr, Gertz EW: Computed tomography: a new method for diagnosing tumor of the heart. Circulation 1981, 63:448-451.
11. Murphy MC, Sweeney MS, Putnam JB Jr, Walker WE, Frazier OH, Ott DA, Cooley DA: Surgical treatment of cardiac tumors: a 25-year experience. Ann Thorac Surg 1990, 49:612-617. discussion 617-618.

12. Flexman AM, Del Vicario G, Schwarz SK: Hemodynamic collapse under anesthesia in a patient with pulmonary artery sarcoma. Can J Anaesth 2009, 56:604-608.

13. Nath MP, Dhawan N, Chauhan S, Kiran U: A large angiosarcoma of the right atrium: anaesthetic management. Hellenic J Cardiol 2011, 52:273-277.

doi:10.1186/1749-8090-9-56

Cite this article as: Xu et al:: Anesthetic management of the removal of a giant metastatic cardiac liposarcoma occupying right ventricle and pulmonary artery. Journal of Cardiothoracic Surgery 2014 9:56.

\section{Submit your next manuscript to BioMed Central and take full advantage of:}

- Convenient online submission

- Thorough peer review

- No space constraints or color figure charges

- Immediate publication on acceptance

- Inclusion in PubMed, CAS, Scopus and Google Scholar

- Research which is freely available for redistribution

Submit your manuscript at www.biomedcentral.com/submit
C Biomed Central 